\title{
New combinations in Zostera (Zosteraceae)
}

\author{
S.W.L. Jacobs ${ }^{1}$ and D.H. Les ${ }^{2}$ \\ ${ }^{1}$ National Herbarium, Royal Botanic Gardens, Sydney, Australia 2000 \\ ${ }^{2}$ University of Connecticut, Department of Ecology and Evolutionary Biology, Storrs, CT 06269- \\ 3043, USA \\ Author for correspondence: Surrey.Jacobs@rbgsyd.nsw.gov.au
}

\begin{abstract}
Systematic studies have clarified interspecific relationships in Zostera, but also allow for different but phylogenetically compatible classifications. Recently, several new species have been assigned to the genus Heterozostera, which some prefer to retain as a subgenus within Zostera; thus, if this taxonomic interpretation is followed, appropriate names do not exist in Zostera.To address this problem, we provide three new combinations (Zostera chilensis, Z. nigricaulis and Z. polychlamys) for species from Chile and Australia, that have been described in Heterozostera. We also present a brief account of the conflicting classifications available for Zosteraceae.
\end{abstract}

\section{Introduction}

By analysing both molecular and morphological data, Les et al. (2002) demonstrated that Heterozostera is nested phylogenetically within Zostera. The DNA and morphological cladograms presented by Les et al. (2002) are consistent with a number of options for maintaining monophyletic taxa within Zosteraceae, and there have been at least three ways proposed for resolving the classificatory problem:

(i) recognise one genus, Zostera (with two or three subgenera), treating Heterozostera as a synonym of the former genus;

(ii) recognise three genera, namely, Zostera, Heterozostera and Nanozostera; or

(iii) recognise two genera, namely, Zostera and Nanozostera (including Heterozostera).

Tomlinson and Posluszny (2001) adopted option (ii) by elevating the former Zostera subgenus Zosterella Aschers. to generic rank as Nanozostera, an approach that has not yet been widely followed. In our estimation, this option appears to be the least optimal because it introduces a new name for a taxon already widely recognised as a subgenus and would require the unnecessary abandonment of taxonomic names that have been in use for more than a century. Furthermore, the proposed genera would be difficult to delimit morphologically; e.g., a morphological phylogenetic analysis depicted the three taxa as an unresolved polytomy (Les et al. 2002). It also seems excessive to segregate the less than 15 total species as three separate genera with rather weak morphological distinctions. 
Consequently, Les et al. (2002) proposed that only one genus should be recognised, namely Zostera (option [i], above). Their recommendation was made because that option provided the highest level of nomenclatural stability and avoided a proliferation of names within this small group of morphologically similar plants.

Phylogenetic analyses by Tanaka et al. (2003) resolved the same basic clades as those found by Les et al. (2002). These authors did not advocate adoption of a specific classification, but suggested yet another option (iii), which was to merge subgenus Zosterella and the genus Heterozostera under the name of the recently described Nanozostera. However, that option would not be valid nomenclaturally, given that such a merger would require the use of the oldest name available at the rank of genus. In this case, that name would be Heterozostera (named by Hartog in 1970) rather than Nanozostera (named by Tomlinson \& Posluszny in 2001).

Phylogenetic analyses by Kato et al. (2003) also mirrored the results of Les et al. (2002), by recovering essentially the same three clades of Zostera species. However, those authors advocated the adoption of the 'option (iii)' classification suggested by Tanaka et al. (2003), i.e., two genera (Zostera, Nanozostera), with Heterozostera merged within the latter. Consequently, these authors also failed to recognise the nomenclatural priority of the name Heterozostera at the genus level. Further nomenclatural confusion is evidenced by their proposed establishment of only two subgenera within Nanozostera (Heterozostera, Zosterella), neither representing the required autonym (i.e., subgenus Nanozostera) which would be established by the presence of the type species of the genus. In any case it is clearly evident that option (iii) should not be considered for classification of Zostera species because it is invalid nomenclaturally.

Kuo (2005) published a revision of Heterozostera, using morphological and anatomical characters to distinguish four taxa from what originally had been considered a single species (Heterozostera tasmanica). This work followed the classification option (ii), retaining Heterozostera as one of the four generic segregates advocated by Tomlinson and Posluszny (2001). However, no rationale for following that particular classification was provided. As a result, Kuo (2005) named three new species of Heterozostera, that, if they are to be treated as species of Zostera, currently lack combinations in that genus.

We make no evaluation of the validity of the new Heterozostera species proposed by Kuo (2005); however, we continue to advocate that any species related phylogenetically to the clade containing the former Heterozostera tasmanica should be assigned to the genus Zostera. A more detailed rationale for our preference is provided in Les et al. 2002), but is summarised here.

The generic distinction of Zostera and Heterozostera has been disputed, mainly because of the uncertainty of the reliability of apparent diagnostic taxonomic characters. Several taxonomists have remarked on the difficulty of separating the morphologically similar Zostera and Heterozostera (Aston 1973; Jacobs \& Williams 1980). Aston (1973) and Phillips and Meñez (1988) essentially followed Hartog (1970) who distinguished the two genera based on a distinction between monopodial rhizomes as found in Zostera compared to sympodial (unbranched) rhizomes in Heterozostera. However, Tomlinson (1982) and Soros-Pottruff and Posluszny (1995) have shown that this oftencited sympodial feature is erroneous and should not be used to distinguish the genera. Robertson (1984) followed Tomlinson's (1982) recommendations and considered both Heterozostera and Zostera as having monopodial, herbaceous rhizomes. Instead, she relied on the difference in cortical vascular bundle number (employed as the 
secondary key character by Hartog 1970) and retinacule shape to separate the genera. However, Yip (1988) later showed that overlap exists in the number of cortical bundles in Zostera (2-4) and Heterozostera (2-12). Therefore Heterozostera, as circumscribed originally by Hartog (1970), cannot be supported.

Although Soros-Pottruff and Posluszny (1995) clarified the rhizome type in Heterozostera and Zostera (both monopodial), their clarification provided for a new method of distinguishing between the taxa, namely, an undulating growth pattern that, in the family, is apparently unique to Heterozostera. Soros-Pottruff and Posluszny (1995) also included the presence of wiry, erect stems, a tendency toward increased cortical vascular bundles, and lack of vascularisation in retinacules as additional features that separate Heterozostera from Zostera. Les et al (2002) added retinacule morphology as another useful diagnostic feature, which is described as lanceolate in Heterozostera and triangular to suborbicular in Zostera (Roberts 1984). Within Zosteraceae, Hartog (1970) described the retinacules as elongate, hence long (2.5$14 \mathrm{~mm}$ long) in Phyllospadix, moderately long $(2-3 \mathrm{~mm})$ in Heterozostera and either short $(0.5-1.75 \mathrm{~mm})$ or absent in Zostera. The longer $(>2 \mathrm{~mm})$ retinacules of Heterozostera appear to effectively separate it from Zostera $(<1.75 \mathrm{~mm})$ without overlap.

Even though some of the distinctions made between Heterozostera and Zostera in past treatments have proven to be flawed, a modified set of characters could be used effectively to separate these taxa taxonomically. In addition to these distinctions, Kuo and McComb (1998) suggest that Heterozostera is probably a hexaploid, a unique ploidy level in the family. Hence, the major issue with Heterozostera is not whether it is distinct taxonomically, but rather which taxonomic rank is most appropriate given the observed differences. Are undulating rhizomes, additional vascular bundles, and long, unvascularised retinacules sufficient to separate Heterozostera and Zostera at the generic level?

The circumscription of ranks (genera, sections, species) always involves some subjectivity, but greater objectivity can be achieved by the satisfaction of phylogenetic criteria that taxa should represent monophyletic groups (Judd et al. 1999). Morphological data alone cannot effectively answer this question because of their low resolving power. If the topology of the majority rule consensus tree (Les et al 2002) is used as a guideline, then Heterozostera must either be combined with Zostera, or four separate genera of Zosteraceae recognised to avoid paraphyletic taxa.

However, the approach taken recently by Tomlinson and Posluszny (2001), seems unnecessarily excessive. Tomlinson and Posluszny (2001) proposed the adoption of a new genus Nanozostera to accommodate species in Zostera subgenus Zosterella. They provided no new data, but essentially echoed the results of Soros-Pottruff and Posluszny (1995) as the basis of their generic segregation. Because neither study analysed phylogenetic relationships, the conclusions were based on perceived morphological incongruities. However, the morphological cladistic analyses of Les et al. (2002) indicate that none of the genera recognised by Tomlinson and Posluszny is particularly well-defined morphologically, especially when compared to the genus Phyllospadix. Nanozostera is defined by only two morphological synapomorphies, Zostera (sensu stricto) by three synapomorphies, and Heterozostera by four synapomorphies. In perspective, Zostera noltii and Z. japonica are differentiated from the other members of Zostera subgenus Zosterella also by only two synapomorphies, yet have never been considered as separate genera. This level of differentiation is miniscule when compared 
to Phyllospadix which is separated from these taxa by 19 morphological apomorphies. Comparatively, the low level of morphological differentiation would support the merger of Heterozostera, plus Nanozostera, into a single genus (Zostera) and with the family consisting of the latter genus and Phyllospadix.

The pattern of nucleotide divergence is similar proportionately; e.g., with Phyllospadix differing substantially from all other Zosteraceae $(21.8-26.7 \%)$ and none of the remaining taxa exhibiting more than $16.8 \%$ (mostly $<8.0 \%$ ) nucleotide divergence (Les et al.2002). Although relative nucleotide divergence can provide interesting evolutionary insights, we believe that major taxonomic distinctions (such as delimitation of genera) should rely principally on morphological characters if any practical utility is to be achieved.

In summary, the phylogenetic analyses of Zosteraceae by Les et al. (2002) resolved the same four clades using molecular or morphological data, either singly or in combination. Although each clade could be recognised as a distinct genus in a cladistic sense, doing so would, in our opinion, create several highly similar and weakly differentiated genera. However, phylogenetic analyses of Zosteraceae by several groups of researchers consistently demonstrate no support for the circumscription of Heterozostera as proposed originally by Hartog (1970). If that genus is to be retained, it must also be redefined to include Zostera subgenus Zosterella if phylogenetic integrity is to be maintained. In such an instance, the generic name Heterozostera would have nomenclatural priority.

Our suggestion is to recognise only two genera in Zosteraceae, namely Zostera and Phyllospadix, which we believe to most usefully depict the major phylogenetic lineages within this family as these two genera are well differentiated at both the morphological and molecular levels. The three subclades within Zostera should continue to be recognised as subgenera, namely as Zostera subg. Zostera, subg. Heterozostera and subg. Zosterella.

Here we provide the new combinations that are necessary for the implementation of this option (i.e. option i).

\section{New combinations (Zostera subgenus Heterozostera)}

Zostera chilensis (J.Kuo) S.W.L.Jacobs \& D.H.Les comb. nov.

Basionym: Heterozostera chilensis J. Kuo (2005; 126-127).

Type: Chile: Aldea, Puerta, Coquimbo Province, drift, January. 1997, H. Kirkman and M. Edding (holo.: US; iso: K, MEL).

This is the name that should be used for all Chilean specimens previously treated as Heterozostera (mostly as H. tasmanica).

Zostera nigricaulis (J.Kuo) S.W.L.Jacobs \& D.H.Les comb. nov.

Basionym: Heterozostera nigricaulis J. Kuo (2005; 110-124).

Type: Australia: South Australia: Kangaroo Island, site 91, 21 November 1977, H. Kirkman (CSIRO 1988) (holo: AD; iso: PERTH).

This is the most widespread and common of the new species and most Australian references to $H$. tasmanica from the eastern States refer to this species. 
Zostera polychlamys (J.Kuo) S.W.L.Jacobs \& D.H.Les comb. nov.

Basionym: Heterozostera polychlamys J.Kuo (2005; 124-126)

Type: Australia: Western Australia: Flinders Bay, drift, 11 December 1990, H. Kirkman (CSIRO 1751; CMM 260, 261) (holo: CANB; iso L, MEL, PERTH).

\section{References}

Aston HI (1973) Aquatic plants of Australia. (Melbourne University Press: Melbourne)

Hartog C Den (1970) The sea-grasses of the world. Verhandelingen der Koninklijke Nederlandse Akademie van Wetenschappen, Afd. Natuurkunde Tweede Reeks, Deel 59, No 1. (NorthHolland Publishing Co.: Amsterdam)

Jacobs SWL \& Williams A (1980) Notes on the genus Zostera s. lat. in New South Wales. Telopea 1: 451-455.

Judd WS, Campbell CS, Kellogg EA \& Stevens PF (1999) Plant systematics: a phylogenetic approach. (Sinauer Associates, Inc.: Sunderland, Massachusetts)

Kato K, Aioi K, Omori Y, Takahata N \& Satta Y (2003) Phylogenetic analyses of Zostera species based on $r b c L$ and matK nucleotide sequences: implications for the origin and diversification of seagrasses in Japanese water. Genes and Genetic Systems 78: 329-342.

Kuo J (2005) A revision of the genus Heterozostera (Zosteraceae). Aquatic Botany 81: 97-140.

Kuo J \& McComb AJ (1998) Zosteraceae. Pp. 496-502 in Kubitzki K (ed.) The Families and Genera of Vascular Plants, vol. IV, Flowering Plants: Monocotyledons, Alismatanae and Commelinanae (except Gramineae). (Springer-Verlag: Berlin)

Les DH, Moody ML, Jacobs SWL \& Bayer RJ (2002) Systematics of seagrasses (Zosteraceae) in Australia and New Zealand. Systematic Botany 27: 468-484.

Phillips RC \& Meñez EG (1988) Seagrasses.Smithsonian Contributions to the Marine Sciences, No. 34. (Smithsonian Institution Press: Washington DC)

Robertson EL (1984) Seagrasses. Pp. 57-122 in Womersley HBS (ed.) The marine benthic flora of southern Australia, part I. (DJ Woolman: South Australia)

Soros-Pottruff CL \& Posluszny U (1995) Developmental morphology of reproductive structures of Zostera and a reconsideration of Heterozostera (Zosteraceae). International Journal of Plant Science 156: 143-158.

Tanaka N, Kuo J, Omori Y, Nakaoka \& Aioi K (2003) Phlogenetic relationships in the genera Zostera and Heterozostera (Zosteraceae) based on matK sequence data. Journal of Plant Research 116: 273-279.

Tomlinson PB (1982) Anatomy of the Monocotyledons VII. Helobiae (Alismatidae) (including the seagrasses). (Clarendon Press: Oxford)

Tomlinson PB \& Posluszny U (2001) Generic limits in the seagrass family Zosteraceae. Taxon 50: 429-437.

Yip M (1988) The anatomy and morphology of the vegetative and floral parts of Zostera L. M.Sc. Thesis, Guelph University, Guelph, Ontario. 